\title{
Performance Evaluation through Characterization ofthe Roll Angle in Heavy Ground Vehicles Using a Wind Tunnel
}

\author{
Israel Ibarra Solis* ${ }^{1}$, Eduardo U. Gonzalez Zavala ${ }^{1}$, Sergio Melgar Zamora ${ }^{1}$, \\ Ubaldo Gil Cruz ${ }^{1}$, Luis G. Bermudez Rodriguez ${ }^{1}$, Yazpik Hernandez Vargas ${ }^{1}$. \\ ${ }^{1}$ Unidad ProfesionalInterdisciplinaria de Ingeniería campus Guanajuato-InstitutoPolitécnico Nacional, Av. \\ Mineral de Valenciana No. 200 Col. Fracc. Industrial Puerto Interior, C.P. 36275 Silao de la Victoria, \\ Guanajuato México, Tel: +52 (55) 57296000 ext. 81389 Fax: +52 (55) 57296000 ext. 81353.
}

\begin{abstract}
The present paper develops experimentation and results to determinate the performance of the roll angle caused by crosswind based on the spring rate of the suspension from the adaptation of a wind tunnel on a heavy ground vehicle, its behavior is calculated with a triaxial accelerometer and a program card (Arduino), finally to verify the behavior comparing mathematical established models which describe the phenomena of the roll over caused by crosswind on the surface of the truck in a precise form, obtaining one model that adjust in a $13 \%$ of our experimentation.
\end{abstract}

Keywords: Roll angle, Wind tunnel, Simulation, Vertical Stiffness

\section{Introduction}

Nowadays several heavy vehicles roll over (they present a rotation on his longitudinal axis) due to the presence of crosswinds in the zones where they circulate. This wind flows generate a lateral force on the trailers of the vehicles generating in occasions that the vehicles rotate and turn over, generating economic losses and inclusive human losses.

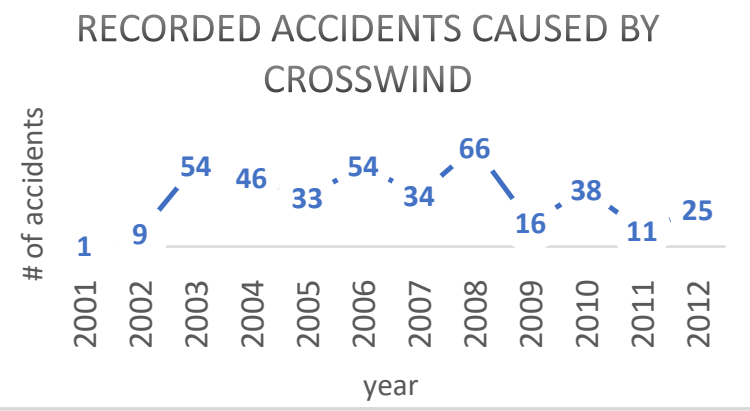

Fig. 1. Graph of the recorded accidents caused by crosswind since 2001 to 2012, México. Fount: IMT (2013).

In Mexico in 2011 there were a total of 1,254 accidents caused by natural means, among those, some were caused by strong winds, a total of $11(0.87 \%)$, some of the attributions caused by accidents due to natural agents is the roll over caused by crosswind. (IMT, 2013), In 2012, this number had increased to 1,422 accidents, with a total of 25 (1.75\%) (Fig. 1), causing losses of 96,191 thousands of dollars, this was an increase from the previous year with more than $200 \%$ (IMT, 2013).

\section{Development}

The development of this project is based mainly on two important points, first to verify if there is a change in the behavior of the roll angle between the two different spring constants, and second to verify if one of the mentioned models have the most closely match with the experiments being performed.

\section{a) General Objective.}

To evaluate the performance of the roll angle in a semi-truck on an articulated truck scale T3-S2, based on the change of the stiffness in the suspension to increase the limit to prevent rollover and thus reducing the tendency to roll caused by crosswind, doing a static and a dynamic test inside a wind tunnel. 


\section{b) Common Problem.}

At the present, the weather conditions are becoming more extreme and with its increase the wind blasts and the accidents too, in which lives are lost and there are millions in losses within the industry at the time they are transporting their goods and/or materials.

\section{c) Theory Models to Verify.}

There are several models representing the roll angle based on vehicle characteristics in this case we analyzed 4 major ones:

Masato Abe (Masato, 2009):

$$
\varphi=\frac{W_{y} h_{s}}{k_{\varphi f}+k_{\varphi r}-W_{s} h_{s}}
$$

T.G. Chondros(T. G. Chondros, 2007):

$$
\theta_{s}=\varphi=\frac{W_{y} h_{s}}{k_{\varphi f}+k_{\varphi r}+W_{s} h_{s}}
$$

Milliken (F. Milliken, 1995):

Chiuan Chen (Xue-Ping \& Li Xin, 2007)

$$
\varphi=\frac{W_{y} h_{s}}{k_{\varphi f}+k_{\varphi r}}
$$

$$
\varphi=\frac{W_{y} * h}{2 K_{t} T^{2}-W_{s} h}
$$

\section{Proposed Methodology}

For the development of the performance evaluation of the roll angle in relation to the change in the stiffness suspension, we had to split into two major parts the methodology.

\section{a) Research Methodology.}

Through the steps of the methodology proposed by Sampieri (Sampieri, 2010), the most important points are developed for the preparation of the experimental phase, taking the technical specification of the semi-truck, the data from the suspension and the development of the tunnel's extension. At the end, we develop a mixed analysis (qualitative-quantitative) based on the results obtained in the experimental phase (Ocampo, 2009).

\section{b) Experimental Phase.}

Testing is proposed based on the actual phenomenon of the crosswind, with a wind tunnel that generates wind currents, an adaptation of an extension that provides a uniform throughout the experimental vehicle, the flow of the wind is measured with a Benetech anemometer, adhering material brewed in petrol substance was put on the surface to prevent the vehicle sliding with the wind, this in order to simulate the coefficient of friction of the wheels on the pavement (Fig. 2).A triaxle accelerometer was characterized to obtain the equation from which we read the roll angle on the tests, obtaining a lineal equation that performs the transformation of the analog data to a degree read with a resolution of 1.0 degrees.

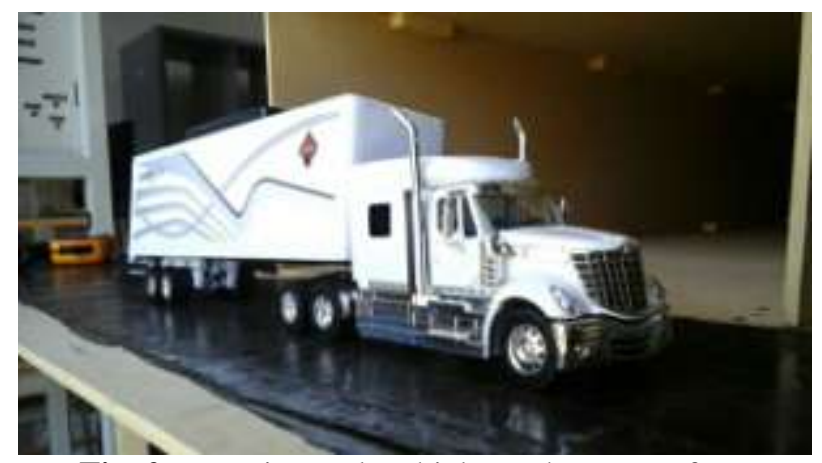

Fig. 2. Experimental Vehicle on the test surface. 
A suspension was adapted to the experimental vehicle to simulate the roll stiffness by applying a wind force (Fig. 3), so the two constants are calculated (Springs) were designed and prepared, that simulate the air springs on the experimental phase.

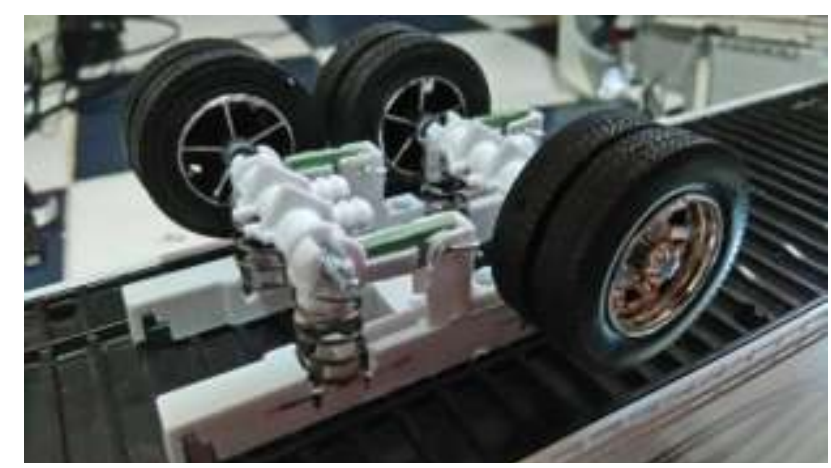

Fig. 3. Suspension fitted to the semi-truck

The main indicators of the experimental phase were:

1) Roll Angle.

2) Wind Velocity.

3) Weight of the Semi-trailer.

4) Weight of the load inside the trailer.

5) Vertical Stiffness of the suspension (Spring Rate).

\section{Experimentation}

The tests were performed in a wind tunnel to speeds of $0-55 \mathrm{~km} / \mathrm{h}$ with leaps of $10 \mathrm{~km} / \mathrm{h}$ and the last leap of 5 $\mathrm{km} / \mathrm{h}$, the weights stablished on the semi-truck were 5 and $8 \mathrm{Kg}$ with two spring stiffness $1 .-1,618 \mathrm{~N} / \mathrm{m}$ simulating an air bag pressure of 40 PSI and 2.- $2,893 \mathrm{~N} / \mathrm{m}$ simulating a second air bag pressure of 80 PSI.Spring constants were exchanged to measure the roll angle in each with the Arduino doing 3 repetitions to ensure the accuracy of the data (Fig. 4), in the same conditions $28^{\circ} \mathrm{C}$ with the same weight.

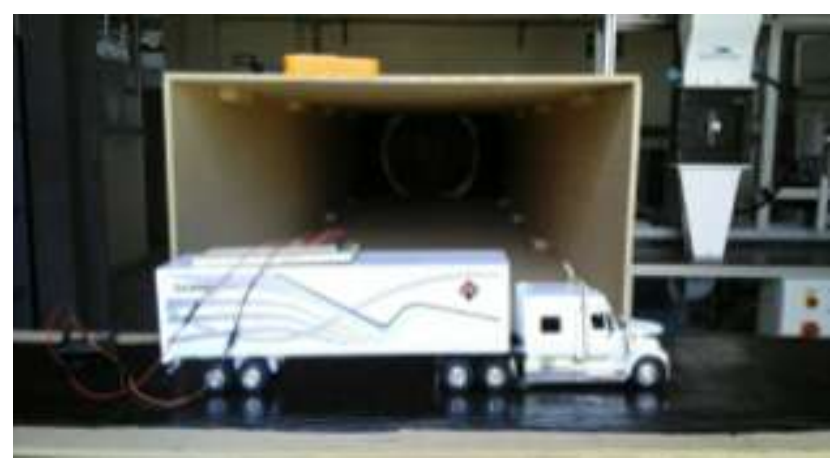

Fig. 4. Experimental phase on the wind tunnel.

\section{Results And Analysis}

According to the tests conducted we obtained graphic behavior with each constant, shown in (Fig. 5) It's seen that the variation between the graphs is minimal being from the study of MSE (Mean Squared Error) is obtained a total variation of $16 \%$ within the experimental $5 \mathrm{Kg}$ and $0 \%$ in the test of $8 \mathrm{Kg}$ among the different constants, this may be because the resolution of the angle reading within our experiments was not the right one to present more variation.

Additionally, a comparison was made on how the vehicle will behave varying side pressure where the wind hits directly (Fig. 6), in this case the suspension airbag upwind present a constant 1,618 N/m and the opposite side $2,893 \mathrm{~N} / \mathrm{m}$, observing a tendency to the side where the wind attacks, so it compensates the inclination generated by the wind, making the test from the angle of $8 \mathrm{Kg}$, to be $55 \mathrm{Km} / \mathrm{h}$ reaching a neutralize aspect at 0 degrees. 


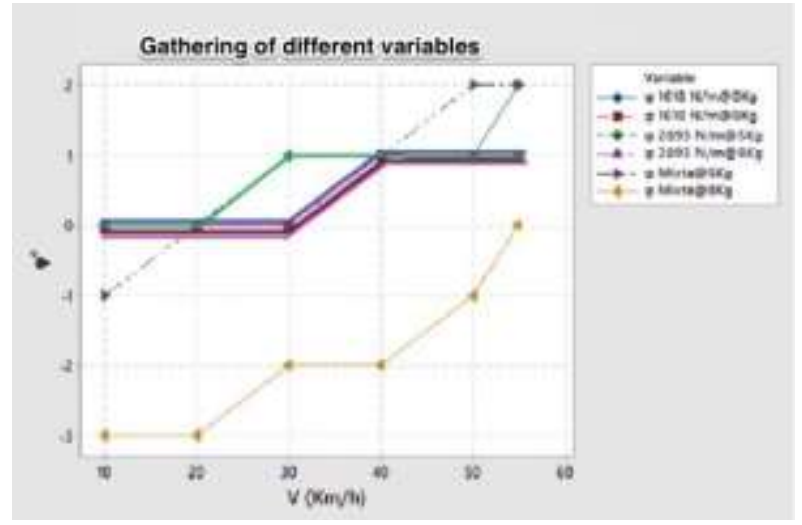

Fig. 5 Graph of roll angle all over the experimentation

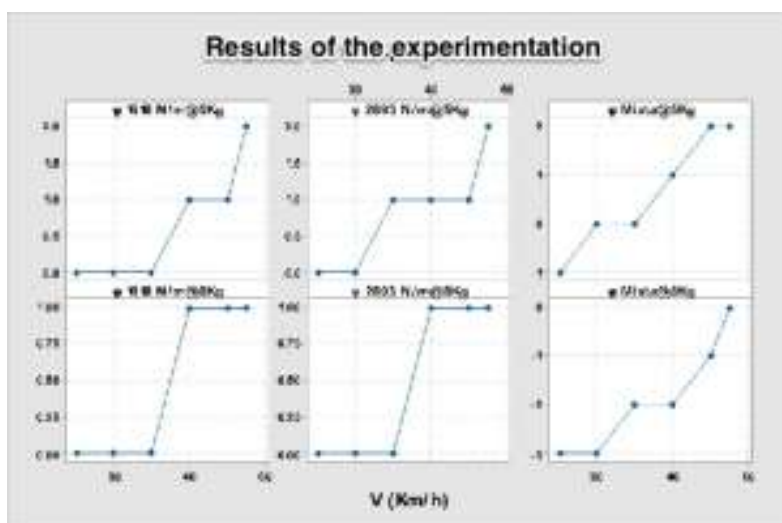

Fig.6 Graph of comparison from the experimental test

Based on tests experimentation a comparison of models previously investigated is performed (Fig. 7), being T.G. Chondros the one that has less error between the experimental and model observed, it was observed 3 times that it match with the tests.

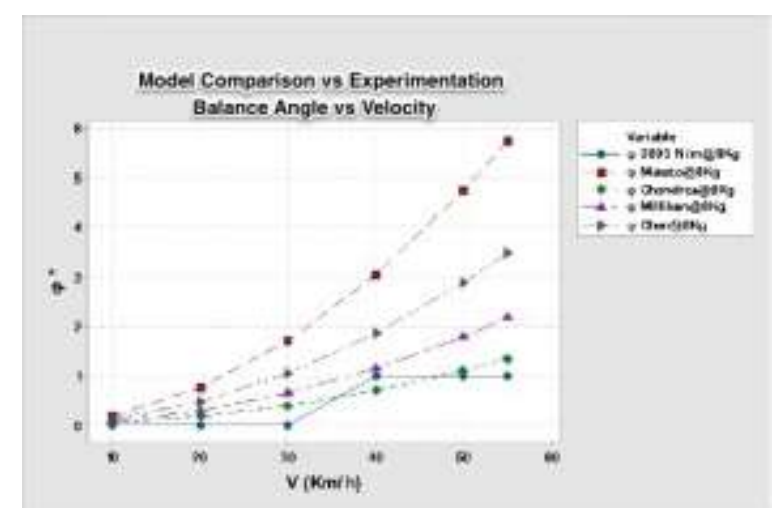

Fig.7 Graph of comparison with the models stablished from $2893 \mathrm{~N} / \mathrm{m}$ to $8 \mathrm{Kg}$

The error obtained for the model ranged from $20.76 \%$ in the test of $1,618 \mathrm{~N} / \mathrm{m}$ to $8 \mathrm{Kg}, 10.87 \%$ in the test of 5 $\mathrm{Kg}$ of the same constant and $6.69 \%$ in the test of 2,893 N/m $8 \mathrm{Kg}$ (Fig. 8, blue line), In the test of $5 \mathrm{Kg}$ and constant of $2,893 \mathrm{~N} / \mathrm{m}$ Milliken is the model that has less variation being $10.82 \%$.

Therefore, the experimentation that was performed and the calculation of the constant of the springs was done adequately and that at least one model was fitted with an error less than $13 \%$ among the three pairings, due to this, T.G. Chondros is the model that until now describes better the phenomenon of the roll angle performance caused by crosswind. 


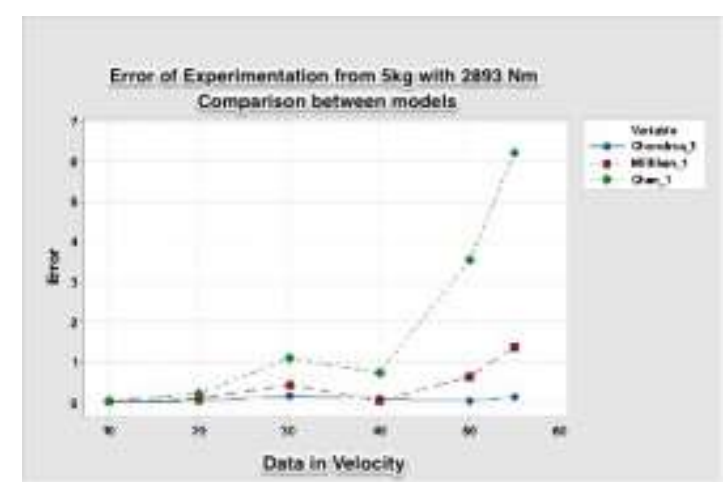

Fig. 8 Graph of test error of $8 \mathrm{~kg}$ with $\mathrm{K}=2893 \mathrm{~N} / \mathrm{m}$

Compared with similar publications on the subject we can say that they are focused on the analysis of lateral acceleration and roll angle, so this study is looking to add information about the behavior of the roll angle and the crosswind, to give a direction to create an innovation about a mechatronic system and another theme of investigation.

\section{Conclusions and Recomendations}

- The behavior of the roll angle with the equal vertical stiffness constant in the axis does not present big variations at speeds under $60 \mathrm{Km} / \mathrm{h}$.

- Decreasing the stiffness of the side where the wind is attacking it is achieved a negative angle that balances or decreases the tendency to rollover in increase speed.

- The data obtained was not decisive to determine a hypothesis that if it is accepted or rejected because the roll over speed wasn't reached, so more testing is necessary.

○ T.G. Chondros Model is the most appropriate to the development of model experiments, because it has greater similarity in the experimental data.

- Excel interface is now a developed tool that allows to determinate the roll angle of heavy vehicles to make prediction of actual behavior.

- The phenomenon of roll over is initially presented from the rear of the body being more burden and more crosswind attack in this area.

- Experimentation is necessary to develop more consistent rigid and speed ranges with higher wind.

\section{References}

[1]. F. Milliken, L. M. (1995). Race Car Vehicle Dynamics. Warrendale, PA: Society of Automotive Engineers.

[2]. IMT. (2013). Anuario Estadistico de Accidentes en Carreteras Federales. Queretaro: IMT.

[3]. Masato, A. (2009). Vehicle Handling Dynamics . Oxford: Elsevier.

[4]. Ocampo, E. (2009). Investigación Caulitativa o Cuantitativa. Córdoba, Colombia: Universidad Nacional de Cordoba.

[5]. Sampieri, R. (2010). Metodología de la Investigación. México, D.F.: Mc. Graw Hill, Quinta Edición.

[6]. T. G. Chondros, G. M. (2007). An Approximate method for the evaluation of the roll stiffness of road tankers. Patras, Greece: Mechanical Engineering and Aeronautics Departament.

[7]. Xue-Ping, Z., \& Li Xin, C. J.-L. (2007). PARAMETRIC DESIGN AND APPLICATION OF STEERING CHARACTERISTIC CURVE IN CONTROL FOR ELECTRIC POWER STEERING. Shangai, China. 